\title{
Structures at Glassy, Supercooled Liquid, and Liquid States in La-Based Bulk Metallic Glasses
}

\begin{abstract}
Q.K. JIANG, Z.Y. CHANG, X.D. WANG, and J.Z. JIANG
Local atomic structures at glassy, supercooled liquid, and liquid states for La-based bulk metallic glasses (BMGs) have been investigated by in-situ high-temperature X-ray diffraction. It is found that the coordination number of about $15.1 \pm 0.1$ for the $\mathrm{La}_{62} \mathrm{Al}_{14} \mathrm{Cu}_{11.7} \mathrm{Ag}_{2.3} \mathrm{Ni}_{5} \mathrm{Co}_{5}$ alloy does not depend on temperature up to liquid temperature, while it decreases slightly with temperature for the $\mathrm{La}_{62} \mathrm{Al}_{14} \mathrm{Cu}_{24}$ and $\mathrm{La}_{62} \mathrm{Al}_{14} \mathrm{Cu}_{20} \mathrm{Ag}_{4}$ alloys. The $S(q)$ data recorded at the supercooled liquid region can be well described by the Debye theory. For the three alloys, the volume expansion coefficient and the slopes of radii variation for the first to third nearest neighboring coordination shells show differences at glassy-to-supercooled liquid transition, while no obvious changes were detected at supercooled liquid-to-liquid transition for them. The linear expansion coefficient value $\left(\beta=1.6 \pm 0.1 \times 10^{-5} \mathrm{~K}^{-1}\right)$ below the glass transition temperature deduced from $S(q)$ data is consistent with that detected by the dilatometer $\left(\beta=1.25 \times 10^{-5} \mathrm{~K}^{-1}\right)$ for the $\mathrm{La}_{62} \mathrm{Al}_{14} \mathrm{Cu}_{11.7} \mathrm{Ag}_{2.3} \mathrm{Ni}_{5} \mathrm{Co}_{5}$ BMG.
\end{abstract}

DOI: $10.1007 / \mathrm{s} 11661-009-0041-9$

(C) The Author(s) 2009. This article is published with open access at Springerlink.com

\section{INTRODUCTION}

UNTIL now, about six alloy systems, forming bulk metallic glasses (BMGs) with diameters larger than $20 \mathrm{~mm}$ by copper mold injection, have been developed. ${ }^{[1-6]}$ The underlying mechanisms for the high glass forming ability (GFA) of these alloys are not completely understood. From a structural point of view, BMGs should have similar structures as their corresponding liquids. So far, very few structural data in liquids for multicomponent BMGs are available, ${ }^{[7-11]}$ resulting in few studies for the correlation of the local atomic structures of liquid with GFA. The coordination number $N_{c}$ is a key parameter used to evaluate the short-range atomic packing density, which is not simultaneously available, to the best of our knowledge, for any BMG systems at glassy, supercooled liquid, and liquid states. On the other hand, the temperature dependences of the coordination number for some nonmetallic amorphous materials have been studied by several groups. ${ }^{[12-14]}$ Ansell et al. ${ }^{[12]}$ and Jakse et al. ${ }^{[13]}$ reported the coordination number decreases with decreasing temperature for supercooled liquid silicon, while Kim et al. ${ }^{[14]}$ presented evidence to emphasize the temperature independence of

Q.K. JIANG and Z.Y. CHANG, Postdoctoral Students, X.D. WANG, Lecturer, and J.Z. JIANG, Professor, are with the International Center for New-Structured Materials (ICNSM), Zhejiang University and Laboratory of New-Structured Materials (LNSM), Department of Materials Science and Engineering, Zhejiang University, Hangzhou 310027, People's Republic of China. Contact e-mail: jiangjz@zju.edu.cn

This article is based on a presentation given in the symposium "Bulk Metallic Glasses VI," which occurred during the TMS Annual Meeting, February 15-19, 2009, in San Francisco, CA, under the auspices of TMS, the TMS Structural Materials Division, TMS/ASM: Mechanical Behavior of Materials Committee.

Article published online November 24, 2009 the coordination number for the same material. In this work, local atomic structures at glassy, supercooled liquid, and liquid states for $\mathrm{La}_{62} \mathrm{Al}_{14} \mathrm{Cu}_{11.7} \mathrm{Ag}_{2.3} \mathrm{Ni}_{5} \mathrm{Co}_{5}$ $\mathrm{BMG}$ are investigated by in-situ high-temperature $\mathrm{X}$-ray diffraction (XRD). There are three reasons to select this alloy: (1) it exhibits excellent GFA, which can be cast into amorphous rods with a diameter of $35 \mathrm{~mm}$; (2) it has a low glass-transition temperature of $430 \mathrm{~K}$ and low melting temperature of about $640 \mathrm{~K}$; and (3) it provides an excellent prototype to investigate the glass transition behavior and liquid properties of BMGs. ${ }^{[5,15]}$ For comparison, the ternary $\mathrm{La}_{62} \mathrm{Al}_{14} \mathrm{Cu}_{24}$ and quaternary $\mathrm{La}_{62} \mathrm{Al}_{14} \mathrm{Cu}_{20} \mathrm{Ag}_{4} \mathrm{BMGs}$ are also studied here. It is found that the coordination number for the $\mathrm{La}_{62} \mathrm{Al}_{14^{-}}$ $\mathrm{Cu}_{11.7} \mathrm{Ag}_{2.3} \mathrm{Ni}_{5} \mathrm{Co}_{5} \mathrm{BMG}$ does not depend on temperature up to liquid temperature, while those for the $\mathrm{La}_{62} \mathrm{Al}_{14} \mathrm{Cu}_{24}$ and $\mathrm{La}_{62} \mathrm{Al}_{14} \mathrm{Cu}_{20} \mathrm{Ag}_{4}$ alloys show a slight decrease with temperature. For the three alloys, the volume expansion coefficient and the slopes of radii variation for the first to third nearest neighboring coordination shells show differences at glassy-to-supercooled liquid transition, while no obvious changes were detected at the supercooled liquid-to-liquid transition for three alloys. The linear expansion coefficient value $\left(\beta=1.6 \pm 0.1 \times 10^{-5} \mathrm{~K}^{-1}\right)$ below the glass transition temperature deduced from $S(q)$ data is consistent with that detected by a dilatometer $\left(\beta=1.25 \times 10^{-5} \mathrm{~K}^{-1}\right)$ for the $\mathrm{La}_{62} \mathrm{Al}_{14} \mathrm{Cu}_{11.7} \mathrm{Ag}_{2.3} \mathrm{Ni}_{5} \mathrm{Co}_{5} \mathrm{BMG}$.

\section{EXPERIMENTAL}

Master ingots with nominal composition of $\mathrm{La}_{62} \mathrm{Al}_{14}$ $\mathrm{Cu}_{24}, \mathrm{La}_{62} \mathrm{Al}_{14} \mathrm{Cu}_{20} \mathrm{Ag}_{4}$, and $\mathrm{La}_{62} \mathrm{Al}_{14} \mathrm{Cu}_{11.7} \mathrm{Ag}_{2.3} \mathrm{Ni}_{5} \mathrm{Co}_{5}$ were arc melted in Ti-gettered high-purity argon atmosphere. Cylindrical alloy rods $3 \mathrm{~mm}$ in diameter and $60 \mathrm{~mm}$ in height were prepared by copper mold suction 
casting. The samples with a thickness of $0.5 \mathrm{~mm}$ cut from the rods were used for differential scanning calorimetry (DSC) and XRD measurements. The DSC measurements were performed on a Netzsch DSC 404 calorimeter at a constant heating rate of $10 \mathrm{~K} / \mathrm{min}$. The onset of glass transition temperature and the crystallization temperature were measured to be $T_{g}=391 \mathrm{~K}$ and $T_{x}=450 \mathrm{~K}$, respectively. Dilatation measurements were conducted with a conventional dilatometer (Netzsch DIL 402C). The initial length of the rod sample was $21 \mathrm{~mm}$, and the compression load during measurement was applied to be $25 \mathrm{~N}$. Calibration was performed using a pure iron sample before the experiments.

The Debye temperature $\left(\theta_{D}\right)$ of the $\mathrm{La}_{62} \mathrm{Al}_{14^{-}}$ $\mathrm{Cu}_{11.7} \mathrm{Ag}_{2.3} \mathrm{Ni}_{5} \mathrm{Co}_{5}$ BMG was calculated by the following equation: ${ }^{[16]}$

$$
\theta_{D}=4.8 \times 10^{-11}\left[\frac{3 n}{4 \pi}\right]^{\frac{1}{3}}\left\{\frac{1}{3}\left[\frac{1}{V_{l}^{3}}+\frac{1}{V_{s}^{3}}\right]\right\}^{-\frac{1}{3}}
$$

where $n$ is the average number of atoms per unit volume, and $V_{l}$ and $V_{s}$ are the longitudinal and transverse sound velocities, respectively, which were measured by a Matec 6600 model ultrasonic system (Matec Instrument Companies, Inc., Northborough, MA) with a measuring sensitivity of $0.5 \mathrm{~ns}$. Based on the Archimedean principle, density $(\rho)$ measurements of the $\mathrm{La}_{62} \mathrm{Al}_{14^{-}}$ $\mathrm{Cu}_{11.7} \mathrm{Ag}_{2.3} \mathrm{Ni}_{5} \mathrm{Co}_{5}$ BMG were performed with a Mettler Toledo XS105 microbalance having a sensitivity of $0.01 \mathrm{mg}$. The $\rho$ value of the alloy at ambient temperature was measured to be about $6.19 \mathrm{~g} / \mathrm{cm}^{3}$. Structural analysis of $\mathrm{La}_{62} \mathrm{Al}_{14} \mathrm{Cu}_{24}, \quad \mathrm{La}_{62} \mathrm{Al}_{14} \mathrm{Cu}_{20} \mathrm{Ag}_{4}$, and $\mathrm{La}_{62} \mathrm{Al}_{14} \mathrm{Cu}_{11.7} \mathrm{Ag}_{2.3} \mathrm{Ni}_{5} \mathrm{Co}_{5}$ specimens with $1 \mathrm{~mm}$ in diameter were conducted by using high-energy $(100 \mathrm{keV})$ synchrotron radiation XRD at the BW5 station of Hasylab (Hamburg). ${ }^{[17]}$ The wavelength used was $0.12398 \AA$. Diffraction patterns were recorded on an image plate MAR 345 , with $150 \times 150 \mu \mathrm{m}^{2}$ pixel size. The experimental setup consists of a high-temperature chamber, and the sample was held for 130 seconds at each corresponding temperature (20 seconds for exposure and 110 seconds for data readout time). The diffraction images were integrated to produce onedimensional powder diffraction patterns, being processed to correct background scattering from air and the windows of the chamber, absorption effects, multiple scattering, and Compton scattering using software packages FIT2D ${ }^{[18]}$ and PDFgetX2. ${ }^{[19]}$

\section{RESULTS AND DISCUSSION}

Figure 1(a) selectively shows the structure factor, $S(q)$, for the $\mathrm{La}_{62} \mathrm{Al}_{14} \mathrm{Cu}_{11.7} \mathrm{Ag}_{2.3} \mathrm{Ni}_{5} \mathrm{Co}_{5}$ sample as a function of temperature. The sample partially crystallizes at $T=423 \mathrm{~K}$, which is a little lower than the crystallization temperature $T_{x}=450 \mathrm{~K}$ estimated by DSC due to the lower heating rate of about $2.5 \mathrm{~K} / \mathrm{min}$ used here for XRD measurements. Between $423 \mathrm{~K} \leq T \leq 463 \mathrm{~K}$, the sample crystallizes, and it melts at temperatures $T \geq 640 \mathrm{~K}$, indicated by the diffused diffraction patterns. Magnifying the first peak in

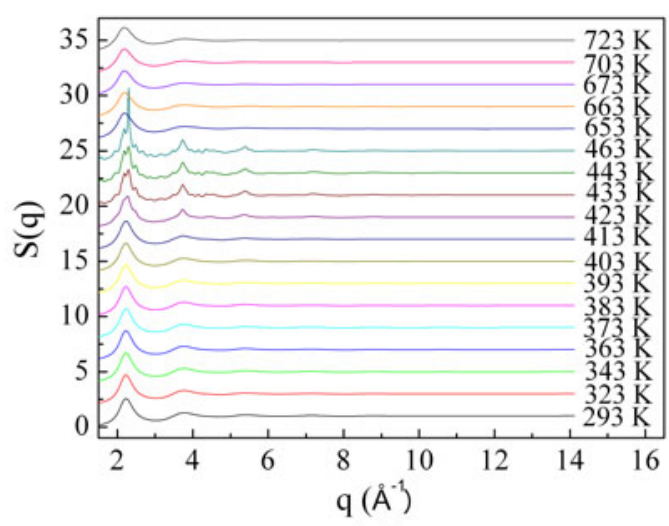

(a)

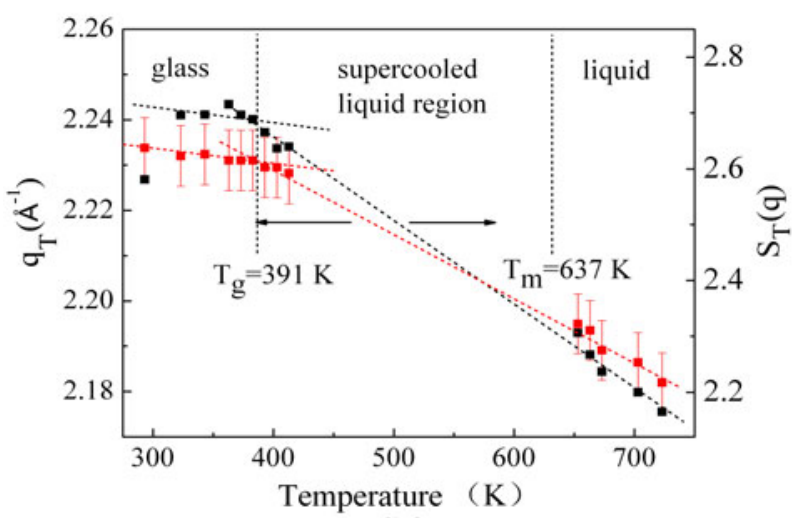

(b)

Fig. 1-(a) Structure factor, $S(q)$, for the $\mathrm{La}_{62} \mathrm{Al}_{14} \mathrm{Cu}_{11.7} \mathrm{Ag}_{2.3} \mathrm{Ni}_{5} \mathrm{Co}_{5}$ alloy as a function of temperature. (b) The height of the first peak, $S_{T}(q)$, and the $q$ values at the position of the first maxima of $S(q)$, $\left(q_{T}\right)$, at various temperatures in the $S(q) \sim \mathrm{q}$ curves for the $\mathrm{La}_{62} \mathrm{Al}_{14} \mathrm{Cu}_{11.7} \mathrm{Ag}_{2.3} \mathrm{Ni}_{5} \mathrm{Co}_{5}$ alloy.

Figure 1, it is found that the position of the maxima of the first diffraction peak slightly shifts to lower $q$ values with increasing temperature at glassy, supercooled liquid, and liquid states. To assess the temperature effect on the structural behavior, the height of the first peak, $S_{T}(q)$, and the $q$ value at the first maxima of $S(q), q_{T}$, at various temperatures in the $S(q) \sim \mathrm{q}$ curves were plotted, as shown in Figure 1(b). Both the $S_{T}(q)$ and $q_{T}$ values slightly decrease with temperature. Above $T_{g}$, the slopes of reduction of $S_{T}(q)$ and $q_{T}$ become bigger. The trend observed in the evolution of $S_{T}(q)$ over the temperature range for the $\mathrm{La}_{62} \mathrm{Al}_{14} \mathrm{Cu}_{11.7} \mathrm{Ag}_{2.3} \mathrm{Ni}_{5} \mathrm{Co}_{5}$ sample is also observed for $\mathrm{La}_{62} \mathrm{Al}_{14} \mathrm{Cu}_{24}, \mathrm{La}_{62} \mathrm{Al}_{14} \mathrm{Cu}_{20} \mathrm{Ag}_{4}$ alloys (not shown here), and is in good agreement with previous measurements. ${ }^{[7]}$ The slope change is detected at $T_{g}$ in the $q_{T} \sim \mathrm{T}$ curve for the present $\mathrm{BMG}$ alloy, which is different from that in the $\mathrm{Pd}_{40} \mathrm{Cu}_{30} \mathrm{Ni}_{10} \mathrm{P}_{20}{ }^{\left[{ }^{7]}\right.}$ The reason for the discrepancy may be attributed to different thermal expansion behaviors of both alloys.

To quantitatively evaluate the volume coefficient of thermal expansion $\alpha$, here, the method proposed by Jiang et al. ${ }^{[20]}$ and Yavari et al. ${ }^{[9]}$ was applied: $q\left(T_{0}\right) / q(T)$ (the $q$ values corresponding to maxima of $S(q)$ in the $S(q) \sim \mathrm{q}$ curves) reflects the relative change of the mean 
interatomic distance at the first coordination shell, which could be proportional to the relative change of sample dimension at various temperatures, deriving the thermal expansion of the glassy structure according to Eq. [2]:

$$
\left[\frac{q\left(T_{0}\right)}{q(T)}\right]^{3}=\left[\frac{L_{T}}{L_{0}}\right]^{3}=\frac{V(T)}{V\left(T_{0}\right)}=1+\alpha\left(T-T_{0}\right)
$$

where $L_{T} / L_{0}$ is the linear relative size change at temperature $T$. The volume expansion $V_{T} / V_{0}$ can be accessed by the third power of $L_{T} / L_{0}$ based on the assumption that the glassy alloys are isotropic. The term $\alpha$ is the volume coefficient of thermal expansion. The term $T_{0}$ is a reference temperature and, in this case, is 293 K. Figure 2 presents the linear relative size change $L_{T} / L_{0}$ and volume expansion $V_{T} / V_{0}$ vs temperatures. The slope of the $L_{T} / L_{0} \sim T$ curve below $400 \mathrm{~K}$ gives the linear coefficient of thermal expansion $\beta=1.6 \pm 0.1 \times$ $10^{-5} \mathrm{~K}^{-1}$, while that in the $V_{T} / V_{0} \sim T$ gives the volume expansion coefficient $\alpha=4.8 \pm 0.3 \times 10^{-5} \mathrm{~K}^{-1}$. These data estimated here are in good agreement with those for other BMGs (e.g., $\quad \alpha=4.2 \pm 0.3 \times 10^{-5} \mathrm{~K}^{-1}$, $\beta=1.4 \pm 0.1 \times 10^{-5} \mathrm{~K}^{-1}$ for $\mathrm{Cu}_{55} \mathrm{Zr}_{30} \mathrm{Ti}_{10} \mathrm{Ni}_{5},{ }^{[10]}$

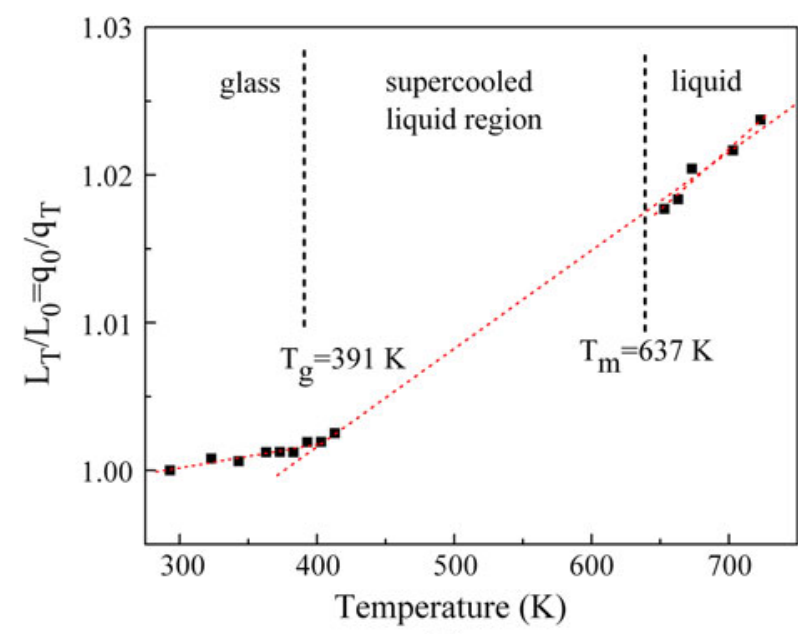

(a)

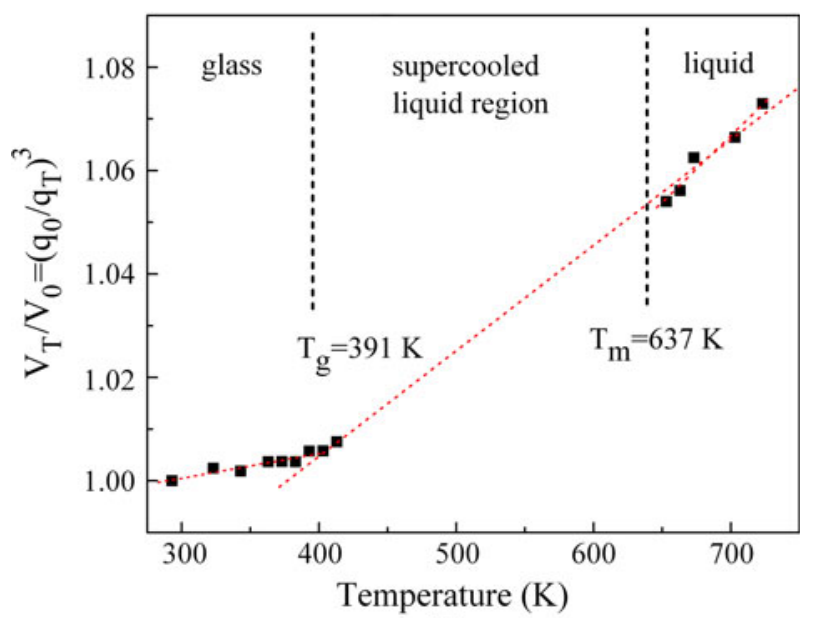

(b)

Fig. 2-(a) Linear relative size change $L_{T} / L_{0}$ and $(b)$ volume expansion $V_{T} / V_{0}$ vs temperature for the $\mathrm{La}_{62} \mathrm{Al}_{14} \mathrm{Cu}_{11.7} \mathrm{Ag}_{2.3} \mathrm{Ni}_{5} \mathrm{Co}_{5}$ alloy. $\alpha=3.1 \pm 0.1 \times 10^{-5} \mathrm{~K}^{-1}$ for $\mathrm{Zr}_{65} \mathrm{Al}_{10} \mathrm{Cu}_{15} \mathrm{Ni}_{10}{ }^{[11]}$ ). At temperatures higher than $T_{m}, \alpha$ and $\beta$ are estimated to be $\beta=8.3 \pm 0.1 \times 10^{-5} \mathrm{~K}^{-1}$ and $\alpha=2.6 \pm 0.3 \times 10^{-4} \mathrm{~K}^{-1}$ for the $\mathrm{La}_{62} \mathrm{Al}_{14} \mathrm{Cu}_{11.7} \mathrm{Ag}_{2.3} \mathrm{Ni}_{5} \mathrm{Co}_{5}$ alloy, respectively. These values are also common for liquid metals. ${ }^{[21]}$ For the $\mathrm{La}_{62} \mathrm{Al}_{14} \mathrm{Cu}_{11.7} \mathrm{Ag}_{2.3} \mathrm{Ni}_{5} \mathrm{Co}_{5}$ alloy, data points in the supercooled liquid region are limited, and thus, the slope in this region was estimated with a larger uncertainty. However, it is clear that the thermal expansion coefficients by fitting the liquid data alone or with a combination of the data at liquid and supercooled liquid states differ from the data for the glassy state.

In order to prove the validity of the data obtained from the XRD, the linear coefficient of thermal expansion was also measured by a dilatometer. Figure 3 shows the DIL curve of the $\mathrm{La}_{62} \mathrm{Al}_{14} \mathrm{Cu}_{11.7} \mathrm{Ag}_{2.3} \mathrm{Ni}_{5} \mathrm{Co}_{5}$ $\mathrm{BMG}$ at a heating rate of $3 \mathrm{~K} / \mathrm{min}$. It can be seen that, in the temperature region from $T=330$ to $390 \mathrm{~K}$, elongation depends linearly on the temperature, which results in the linear thermal expansion coefficient for $\mathrm{La}_{62} \mathrm{Al}_{14} \mathrm{Cu}_{11.7} \mathrm{Ag}_{2.3} \mathrm{Ni}_{5} \mathrm{Co}_{5} \mathrm{BMG}$ as $\beta=1.25 \times 10^{-5} \mathrm{~K}^{-1}$ at a heating rate of $3 \mathrm{~K} / \mathrm{min}$. However, above $T=390 \mathrm{~K}$, it departs from linearity, which is partially due to the annihilation of free volume via relaxation below the glass transition temperature. At high temperatures in the supercooled liquid region, the data are not valid for expansion measurements because deformation for soft supercooled liquid occurs due to the load applied. We found that the expansion coefficient obtained from in-situ XRD experiments for the $\mathrm{La}_{62} \mathrm{Al}_{14} \mathrm{Cu}_{11.7} \mathrm{Ag}_{2.3} \mathrm{Ni}_{5} \mathrm{Co}_{5} \mathrm{BMG}$ is in good agreement with the data obtained from the dilatometer, which confirms the validity of the XRD method to deduce the thermal expansion behavior of the amorphous phase.

The Debye theory ${ }^{[20]}$ was also employed to describe the temperature dependence of the X-ray scattering factor. The structure factor at temperature $T_{2}\left(S_{T_{2}(q)}\right)$ can be calculated from that at another temperature $T_{1}$ $\left(S_{T_{1}(q)}\right)$ using Eqs. [3] and [4]: ${ }^{[7,10]}$

$$
\frac{S_{T_{2}(q)}-1}{S_{T_{1}(q)}-1}=\exp \left\{-2\left[W_{T_{2}(q)}-W_{T_{1}(q)}\right]\right\}
$$

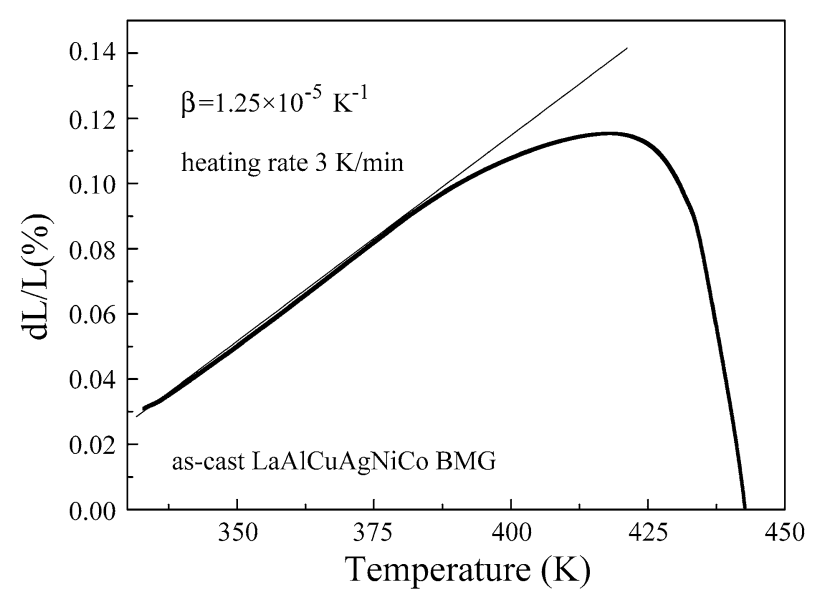

Fig. 3-Linear thermal expansion coefficient of the $\mathrm{La}_{62} \mathrm{Al}_{14} \cdot \mathrm{Cu}_{11.7} \mathrm{Ag}_{2.3} \mathrm{Ni}_{5} \mathrm{Co}_{5}$ alloy measured at a heating rate of $3 \mathrm{~K} / \mathrm{min}$. 


$$
W_{T}=\frac{3 \hbar^{2} q^{2}}{2 m_{a} k_{B} \theta}\left(\frac{T}{\theta}\right)^{2} \int_{0}^{\theta / T}\left(\frac{1}{2}+\frac{1}{e^{z}-1}\right) z d z
$$

where $\exp \left(-2 W_{T}\right)$ is the Debye-Waller factor, $\hbar$ is the Planck's constant, and $m_{a}$ is the mean atomic mass. The Debye temperature for the $\mathrm{La}_{62} \mathrm{Al}_{14} \mathrm{Cu}_{11.7} \mathrm{Ag}_{2.3} \mathrm{Ni}_{5} \mathrm{Co}_{5}$ BMG alloy was calculated by acoustic velocities measured using a Matec 6600 model ultrasonic system, and the value for the alloy was determined to be about $158 \mathrm{~K}$, being consistent with the values reported for some other rare-earth-based BMGs. ${ }^{[22]}$ Based on Eqs. [3] and [4] and $S(q)$ data at $T_{1}=293 \mathrm{~K}$, we calculated the structure factors at $T_{2}=363,413$, and $673 \mathrm{~K}$, respectively, in Figure 4, corresponding to their states from glassy, supercooled liquid, and liquid stage. It is seen that at lower temperatures around $T_{g}$, the calculated structure factors fit well with the experimental ones, implying that the Debye theory is still validated at the glass and supercooled liquid stages. An obvious difference was detected between the calculated $S(q)$ and experimental $S(q)$ at $T=673 \mathrm{~K}$, indicating the invalidity of the Debye theory or the internal structural change in the liquid state as compared to the glassy state. Similar conclusions were also derived in the literature. ${ }^{[7]}$

To further analyze the temperature effect on structural behavior, the real-space atomic pair correlation function $g(r)$ was obtained by Fourier transformation:

$$
g(r)=\frac{\rho(r)}{\rho_{0}}=1+\frac{1}{2 \pi^{2} \rho_{0} r} \int_{0}^{\infty}(q[S(q)-1) \sin (q r) d q[5]
$$

where $\rho(r)$ is the radial density function and $\rho_{0}$ the average atomic number density. Figure 5(a) shows the $g(r)$ curves at some selected temperatures $T=293,363$, 413 , and $673 \mathrm{~K}$, respectively. Based on the hard sphere model using the nominal atomic radii, one can find that La-La (3.76 $)$, La-Cu (3.16 $)$, and La-Al (3.31 $)$ bonds dominate the first peak of the $g(r)$ curves, with their corresponding weight factors $\mathrm{W}_{\mathrm{La}-\mathrm{La}}, \mathrm{W}_{\mathrm{La}-\mathrm{Cu}}$, and

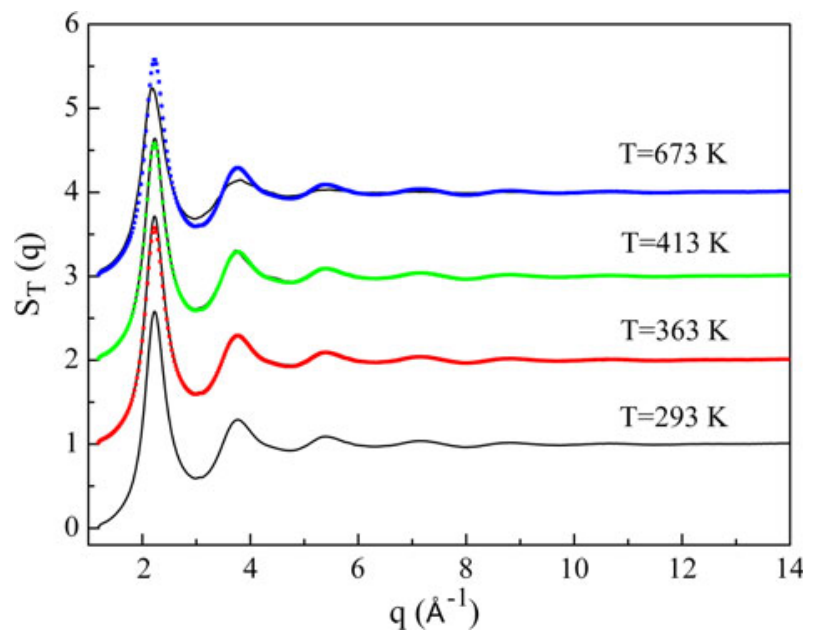

Fig. 4 - Calculated $S(q)$ (colorful ones) using Eqs. [3] and [4] and experimental $S(q)$ (black ones) at various temperatures for the $\mathrm{La}_{62} \mathrm{Al}_{14} \mathrm{Cu}_{11.7} \mathrm{Ag}_{2.3} \mathrm{Ni}_{5} \mathrm{Co}_{5}$ alloy.
$\mathrm{W}_{\text {La-Al }}$ to be $0.64,0.12$, and 0.07 , respectively. The shoulders appearing at lower temperatures around 3.1 to $3.2 \AA$ in the first peak of $g(r)$ were mainly due to $\mathrm{La}-\mathrm{Cu}$ bonds and became less pronounced above the melting point. A slight broadening of the first $g(r)$ peak is also observed with an increase in temperature. Figure 5(b) shows the relative $r_{i}(i=1,2,3$, and 4$)$ variation $(\Delta r(T) / r(293 \mathrm{~K}))$ at various temperatures normalized by $r_{i}$ at $T=293 \mathrm{~K}$. It is seen that the $r_{1}$ at the first maximum position, corresponding to the nearest neighbor distance, decreases while the others neighbor distances of higher coordination shells increase at elevated temperatures. The trends observed here can also be reflected by those in the $\mathrm{La}_{62} \mathrm{Al}_{14} \mathrm{Cu}_{24}$, $\mathrm{La}_{62} \mathrm{Al}_{14} \mathrm{Cu}_{20} \mathrm{Ag}_{4}$ alloys and are consistent with the results in the $\mathrm{Pd}_{40} \mathrm{Cu}_{30} \mathrm{Ni}_{10} \mathrm{P}_{20}$ alloy. ${ }^{[7]}$ Generally speaking, however, with increasing temperature, the average interatomic distances at various coordination shells should increase. It is found from experimental results that the relative variation $\left(\Delta r_{1}(T) / r_{1}(293 \mathrm{~K})\right)$ decreases

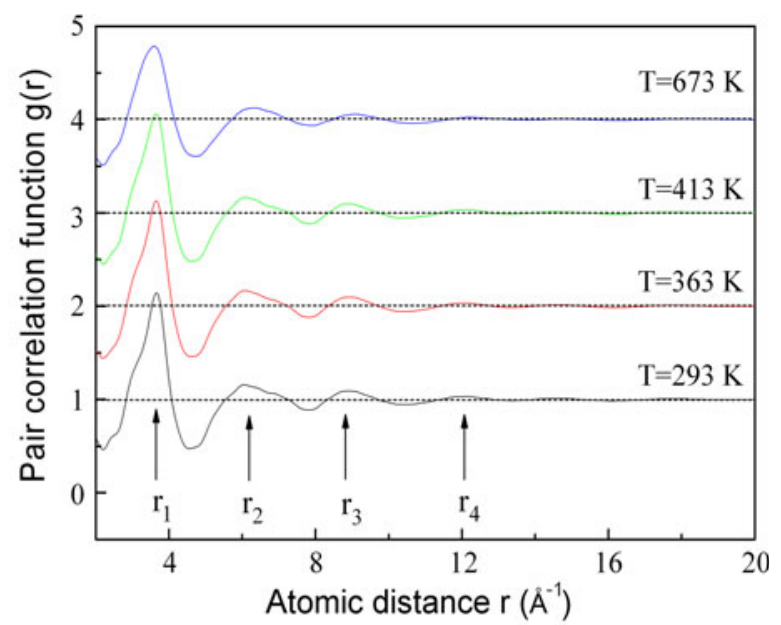

(a)

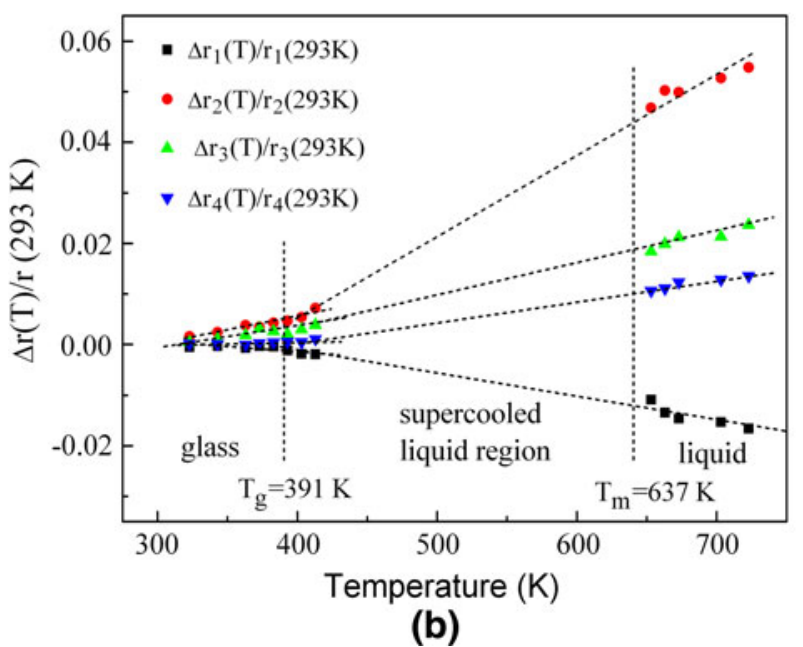

Fig. 5- (a) Pair correlation function, $g(r)$, curves at temperatures $T=293,363,413$, and $673 \mathrm{~K}$, respectively, for the $\mathrm{La}_{62} \mathrm{Al}_{14^{-}}$ $\mathrm{Cu}_{11.7} \mathrm{Ag}_{2.3} \mathrm{Ni}_{5} \mathrm{Co}_{5}$ alloy. (b) The relative $r_{i}(i=1,2,3$, and 4$)$ variation $\left((r(T) / r(293 \mathrm{~K}))\right.$ at various temperatures normalized by $r_{i}$ at $T=293 \mathrm{~K}$ for the $\mathrm{La}_{62} \mathrm{Al}_{14} \mathrm{Cu}_{11.7} \mathrm{Ag}_{2.3} \mathrm{Ni}_{5} \mathrm{Co}_{5}$ alloy. 
for the first peak of the $g(r)$ in at least $\mathrm{La}_{62} \mathrm{Al}_{14} \mathrm{Cu}_{11.7^{-}}$ $\mathrm{Ag}_{2.3} \mathrm{Ni}_{5} \mathrm{Co}_{5}, \quad \mathrm{La}_{62} \mathrm{Al}_{14} \mathrm{Cu}_{24}, \quad \mathrm{La}_{62} \mathrm{Al}_{14} \mathrm{Cu}_{20} \mathrm{Ag}_{4}$, and $\mathrm{Pd}_{40} \mathrm{Cu}_{30} \mathrm{Ni}_{10} \mathrm{P}_{20}$ alloys. What is the origin for this discrepancy?

It is known that the first peak of $g(r)$ is often not symmetric in metallic glasses because of the existence of various interatomic pair contributions. Thus, the position for the maximum intensity might not represent the temperature dependence of the average interatomic distance for a given coordination shell. Thus, we further estimated the average interatomic distances for the first, second, and third coordination shells in the $g(r)$ curves at different temperatures using Eq. [6]:

$$
R_{\mathrm{aver}}=\frac{\sum_{i} r_{i} \times g_{i}(r) \times \Delta r_{i}}{\sum_{i} g_{i}(r) \times \Delta r_{i}}=\frac{\sum_{i} r_{i} \times g_{i}(r)}{\sum_{i} g_{i}(r)}
$$

The $R_{\text {aver }}$ values are treated as the average interatomic distances for different coordination shells, which are weighted by area $A=g_{i}(r) \times \Delta r_{i}$, where $\Delta r_{i}$ is a constant and the values of $r_{i}$ and $g_{i}(r)$ are deduced from the $g(r) v s r$ curve. Figures 6(a) through (c) show the $R_{\text {aver }}$ of the first, second, and third peaks of the pair correlation function, $g(r)$, as a function of temperature for $\mathrm{La}_{62} \mathrm{Al}_{14} \mathrm{Cu}_{11.7} \mathrm{Ag}_{2.3} \mathrm{Ni}_{5} \mathrm{Co}_{5}$ alloy, respectively. It is clear that the average radii for the first, second, and third coordination shells increase with temperature, which should be due to thermal expansion. The slopes normalized by the $R_{\text {aver }}$ value at $293 \mathrm{~K}$ for the first, second, and third peaks as a function of temperature are deduced to be $4.1 \pm 0.7 \times 10^{-5}, 3.0 \pm 0.5 \times 10^{-5}$, and $4.6 \pm 0.8 \times 10^{-5} \mathrm{~K}^{-1}$, respectively, below the glass transition temperature, while those above the glass transition temperatures are $3.8 \pm 0.9 \times 10^{-5}, 4.5 \pm 0.7 \times 10^{-5}$, and $7.4 \pm 0.9 \times 10^{-5} \mathrm{~K}^{-1}$, respectively. A kink is detected at around the glass transition temperature from the data of $R_{\text {aver }}$ as a function of temperature, although it is not very clear for the first peak shell.

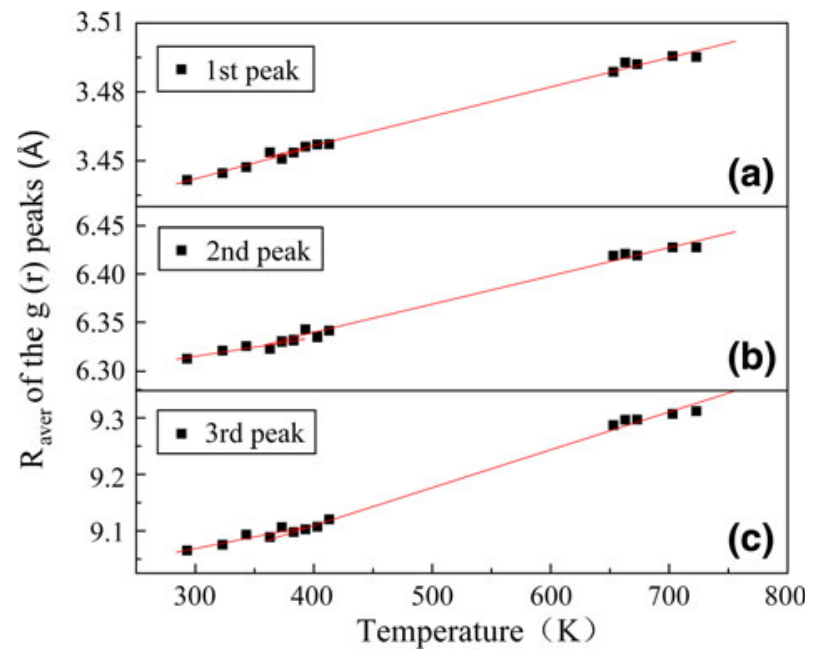

Fig. 6-The average $r$ values $\left(R_{\text {aver }}\right)$ of the $(a)$ first peak, $(b)$ second peak, and $(c)$ third peak of the pair correlation function, $g(r)$, as a function of temperature for the $\mathrm{La}_{62} \mathrm{Al}_{14} \mathrm{Cu}_{11.7} \mathrm{Ag}_{2.3} \mathrm{Ni}_{5} \mathrm{Co}_{5}$ alloy at glassy, supercooled liquid, and liquid states.
As compared with the linear thermal expansion coefficients of $\beta=1.25 \times 10^{-5} \mathrm{~K}^{-1}$ deduced by a dilatometer and $\beta=1.6 \pm 0.1 \times 10^{-5} \mathrm{~K}^{-1}$ deduced by $S(q)$ data for $\mathrm{La}_{62} \mathrm{Al}_{14} \mathrm{Cu}_{11.7} \mathrm{Ag}_{2.3} \mathrm{Ni}_{5} \mathrm{Co}_{5} \mathrm{BMG}$ below the glass transition temperature, it is clear that the values deduced by average interatomic distances for the first, second, and third coordination shells in the $g(r)$ curves are larger, indicating that the average interatomic distances expand larger than the macroscopic length. More studies are required to uncover the origin of this discrepancy.

Generally speaking, the larger the relative coordination number $N_{c}$, the higher the packing density. To quantitatively evaluate the short-range atomic packing density at various temperatures, we could deduce the relative coordination number $N_{c}$ by integrating the radial distribution function (RDF) over the limit of the first peak, where the RDF can be described by Eq. [7]:[13]

$$
\mathrm{RDF}=4 \pi r^{2} \rho_{0}\left[1+\frac{G(r)}{4 \pi r \rho_{0}}\right]
$$

The curves of $N_{c}$ for $\mathrm{La}_{62} \mathrm{Al}_{14} \mathrm{Cu}_{24}, \mathrm{La}_{62} \mathrm{Al}_{14} \mathrm{Cu}_{20} \mathrm{Ag}_{4}$, and $\mathrm{La}_{62} \mathrm{Al}_{14} \mathrm{Cu}_{11.7} \mathrm{Ag}_{2.3} \mathrm{Ni}_{5} \mathrm{Co}_{5}$ alloys as a function of $T$ are shown in Figure 7 together with the relative variation of coordination number, $\Delta N_{c}\left(\Delta N_{c}=\left\{N_{c}(T)-\right.\right.$ $\left.N_{c}(293 K)\right\} / N_{c}(293 K)$ ), as a function of temperature in the inset of Figure 7. The $N_{c}$ value at $293 \mathrm{~K}$ is approximately $15.1 \pm 0.1$, and no obvious changes were observed as the temperature increased from the glassy state to the supercooled liquid state, even to a liquid state within the experimental limit for the $\mathrm{La}_{62} \mathrm{Al}_{14^{-}}$ $\mathrm{Cu}_{11.7} \mathrm{Ag}_{2.3} \mathrm{Ni}_{5} \mathrm{Co}_{5}$ alloy. This result is consistent with that reported in the $\mathrm{Zr}$-based $\mathrm{BMG}^{[8]}$ (a temperature range covering glassy and supercooled liquid states) and liquid silicon. ${ }^{[13]}$ However, for $\mathrm{La}_{62} \mathrm{Al}_{14} \mathrm{Cu}_{24}$ and $\mathrm{La}_{62} \mathrm{Al}_{14} \mathrm{Cu}_{20} \mathrm{Ag}_{4}$ alloys, the coordination numbers are $14.4 \pm 0.1$ and $14.8 \pm 0.1$, respectively, which are slightly lower than that for the $\mathrm{La}_{62} \mathrm{Al}_{14} \mathrm{Cu}_{11.7} \mathrm{Ag}_{2.3} \mathrm{Ni}_{5^{-}}$ $\mathrm{Co}_{5}$ alloy. It seems that the higher the coordination

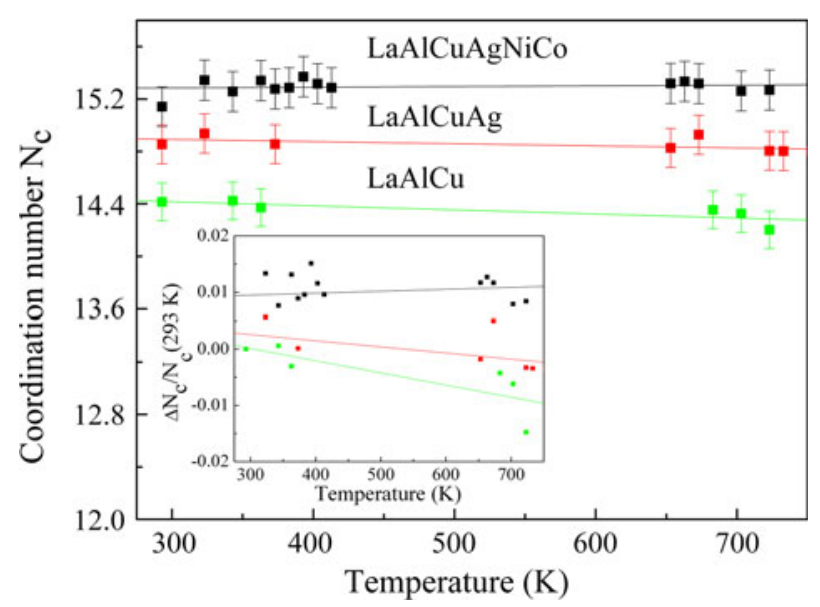

Fig. 7-Relative coordination number $N_{c}$ as a function of temperature for the $\mathrm{La}_{62} \mathrm{Al}_{14} \mathrm{Cu}_{24}, \mathrm{La}_{62} \mathrm{Al}_{14} \mathrm{Cu}_{20} \mathrm{Ag}_{4}$, and $\mathrm{La}_{62} \mathrm{Al}_{14^{-}}$ $\mathrm{Cu}_{11.7} \mathrm{Ag}_{2.3} \mathrm{Ni}_{5} \mathrm{Co}_{5}$ alloy at glassy, supercooled liquid, and liquid states. The inset shows the relative $N_{c}$ variations normalized by $N_{c}$ at $T=293 \mathrm{~K}$. 
number for the first shell, the higher the GFA. This correlation is consistent with common sense, i.e., the higher the dense atomic packing, the higher the GFA. In addition, it seems that the coordination numbers for $\mathrm{La}_{62} \mathrm{Al}_{14} \mathrm{Cu}_{24}$ and $\mathrm{La}_{62} \mathrm{Al}_{14} \mathrm{Cu}_{20} \mathrm{Ag}_{4}$ alloys slightly decrease with temperature despite scattering data. More studies are needed to clarify the relationship between the GFA and coordination number variation.

\section{CONCLUSIONS}

$\mathrm{La}_{62} \mathrm{Al}_{14} \mathrm{Cu}_{11.7} \mathrm{Ag}_{2.3} \mathrm{Ni}_{5} \mathrm{Co}_{5}$ BMG with low glass transition temperatures was selected to investigate local atomic structures at glassy, supercooled liquid, and liquid states by in-situ high-temperature XRD. It is found that the nearest neighbor coordination number of about $15.1 \pm 0.1$ does not depend on temperature up to liquid temperature for the $\mathrm{La}_{62} \mathrm{Al}_{14} \mathrm{Cu}_{11.7} \mathrm{Ag}_{2.3} \mathrm{Ni}_{5} \mathrm{Co}_{5}$ BMG, while those for the $\mathrm{La}_{62} \mathrm{Al}_{14} \mathrm{Cu}_{24}$ and $\mathrm{La}_{62} \mathrm{Al}_{14^{-}}$ $\mathrm{Cu}_{20} \mathrm{Ag}_{4}$ alloys slightly decrease with temperature. For the three alloys, the volume expansion coefficient and the slopes of radii variation for the second and third nearest neighboring coordination shells show differences at glassy-to-supercooled liquid transition. The linear expansion coefficient value $\left(\beta=1.6 \pm 0.1 \times 10^{-5} \mathrm{~K}^{-1}\right)$ below the glass transition temperature deduced from $S(q)$ data is consistent with that detected by the dilatometer $\left(\beta=1.25 \times 10^{-5} \mathrm{~K}^{-1}\right)$. From $g(r)$ data, due to the asymmetry of the first, second, and third shells, the positions for the maximum intensity at different shells might not represent the temperature dependence of the average interatomic distance for a given coordination shell. A new method using weighted average interatomic distances at different shells was proposed. It is found that the average interatomic distances at different shells do follow the normal thermal expansion during heating, but they expand larger than the macroscopic length or volume expansion.

\section{ACKNOWLEDGMENTS}

The authors thank HASYLAB (Hamburg, Germany), BSRF (Beijing), NSRL (Hefei, People's Republic of China), and KEK (Tsukuba, Japan) for use of the synchrotron radiation facilities. Financial support from the National Natural Science Foundation of China (Grant Nos. 50,341,032, 50,425,102, 50,601,021, $50,701,038$, and 60,776,014), Zhejiang UniversityHelmholtz Cooperation Fund, Ministry of Education of China (Program for Changjiang Scholars and the Research Fund for the Doctoral Program of Higher Education), and The Department of Science and
Technology of Zhejiang Province and Zhejiang University is gratefully acknowledged.

\section{OPEN ACCESS}

This article is distributed under the terms of the Creative Commons Attribution Noncommercial License which permits any noncommercial use, distribution, and reproduction in any medium, provided the original author(s) and source are credited.

\section{REFERENCES}

1. A. Peker and W.L. Johnson: Appl. Phys. Lett., 1993, vol. 63, pp. 2342-44.

2. N. Nishiyama and A. Inoue: Mater. Trans. JIM, 1996, vol. 37, pp. 1531-39.

3. F. Guo, S.J. Poon, and G.J. Shiflet: Appl. Phys. Lett., 2003, vol. 83 , pp. 2675-77.

4. H. Ma, L.L. Shi, J. Xu, Y. Li, and E. Ma: Appl. Phys. Lett., 2005, vol. 87, pp. 181915-1-181915-3.

5. Q.K. Jiang, G.Q. Zhang, L. Yang, X.D. Wang, K. Saksl, H. Franz, R. Wunderlich, H. Fecht, and J.Z. Jiang: Acta Mater., 2007, vol. 55, pp. 4409-18.

6. Q.K. Jiang, X.P. Nie, Y.G. Li, Y. Jin, Z.Y. Chang, X.M. Huang, and J.Z. Jiang: J. Alloy Compd., 2007, vol. 443, pp. 191-94.

7. N. Mattern, H. Hermann, S. Roth, J. Sakowski, M.P. Macht, P. Jovari, and J.Z. Jiang: Appl. Phys. Lett., 2003, vol. 82, pp. 2589-91.

8. H. Schumacher, U. Herr, D. Oelgeschlager, A. Traverse, and K. Samwer: J. Appl. Phys., 1997, vol. 82, pp. 155-62.

9. A.R. Yavari, A.L. Moulec, A. Inoue, N. Nishiyama, N. Lupu E. Matsubara, W.J. Botta, G. Vaughan, M.D. Michiel, and A. Kvick: Acta Mater., 2005, vol. 53, pp. 1611-19.

10. K. Hajlaoui, T. Benameur, G. Vaughan, and A.R. Yavari: Scripta Mater., 2004, vol. 51, pp. 843-48.

11. D.V. Louzguine, A.R. Yavari, K. Ota, G. Vaughan, and A. Inoue: J. Non-Cryst. Solids, 2005, vol. 351, pp. 1639-45.

12. S. Ansell, A. Krishnan, J.J. Felten, and D. Price: J. Phys. Condens. Matter, 1998, vol. 10, pp. L73-L78.

13. N. Jakse, L. Hennet, and D.L. Price: Appl. Phys. Lett., 2003, vol. 83, pp. 4734-36.

14. T.H. Kim, G.W. Lee, B. Sieve, A.K. Gangopadhyay, R.W. Hyers, T.J. Rathz, J.R. Rogers, D.S. Robinson, K.F. Kelton, and A.I. Goldman: Phys. Rev. Lett., 2005, vol. 95, pp. 085501-085504.

15. Q.K. Jiang, G.Q. Zhang, L.Y. Chen, J.Z. Wu, H.G. Zhang, and J.Z. Jiang: J. Alloy Compd., 2006, vol. 424, pp. 183-86.

16. D. Schreiber: Elastic Constants and Their Measurement, McGrawHill, New York, NY, 1973.

17. R. Bouchard, D. Hupfeld, T. Lippmann, J. Neuefeind, H.B. Neumann, H.F. Poulsen, U. Rutt, T. Schmidt, J.R. Schneider, J. Sussenbach, and M.V. Zimmermann: Synchrotron. Radiat., 1998, vol. 5, pp. 90-101.

18. A.P. Hammersley, S.O. Svensson, M. Hanfland, A.N. Fitch, and D. Häusermann: High. Press. Res., 1996, vol. 14, pp. 235-48.

19. I.K. Jeong, J. Thompson, A.M.P. Turner, and S.J.L. Billinge: J. Appl. Crystallogr., 2001, vol. 34, pp. 536-36.

20. J.Z. Jiang, W. Roseker, M. Sikorski, Q.P. Cao, and F. Xu: Appl. Phys. Lett., 2004, vol. 84, pp. 1871-73.

21. R.K. Kirby, R.G. Lerner, and G.L. Trigg: Encyclopedia of Physics Thermal Expansion, 2nd ed., VCH, New York, NY, 1990.

22. B. Zhang, R.J. Wang, D.Q. Zhao, M.X. Pan, and W.H. Wang: Phys. Rev. B, 2004, vol. 70, pp. 224208-1-224208-7. 